\title{
Curcuma longa supplement increases anxiety-like behavior and blood glucose level in Swiss albino mice
}

\author{
Usman Adamu Garkuwa ${ }^{1,2, *}$, Buhari Ibrahim ${ }^{1}$, Aisha Nasir Balanmalam ${ }^{1}$, \\ Sayyadatu Razan Muhammad ${ }^{1}$, Mustapha Muazu ${ }^{1}$, Adamu Hassan Garkuwa ${ }^{3}$ \& Adamu Bello Yakubu ${ }^{1,2}$ \\ ${ }^{1}$ Department of Physiology, Faculty of Basic Medical Sciences, Bauchi State University Gadau, Bauchi State, Nigeria. \\ ${ }^{2}$ Department of Human Physiology, Faculty of Basic Medical Sciences, Ahmadu Bello University Zaria, Nigeria. \\ ${ }^{3}$ Abubakar Tafawa Balewa University Teaching Hospital Bauchi, Bauchi State, Nigeria. \\ * Correspondence: garkuwa040@gmail.com; Tel.: +2348036449274
}

Received: 24 October 2020; Accepted: 9 February 2021; Published: 26 February 2021

Edited by: King-Hwa Ling (Universiti Putra Malaysia, Malaysia)

Reviewed by: Norshariza Nordin (Universiti Putra Malaysia, Malaysia);

Usman Bala (Gombe State University, Nigeria); Zurina Hassan (Universiti Sains Malaysia, Malaysia)

https://doi.org/10.31117/neuroscirn.v4i1.60

\begin{abstract}
Curcuma longa (C. longa), also known as curcumin, is a lipophilic polyphenol substance proven to have cholesterol-lowering, anti-diabetic, anti-inflammatory, anti-oxidant, and anti-cancer properties in both in vitro and in vivo models. Most previous studies investigated the effect of $C$. longa on diabetic mice and therefore, there is a need to investigate the effect of $C$. longa on normoglycemic mice. Depression is a common consequence of anxiety that affects $21 \%$ of the world's population. Since the prevalence of diabetes and depression is on the rise globally, it is important to search for safer and cost-effective management for these disorders. In doing so, it is therefore essential to investigate its effect in normoglycemic mice. The current study determines the effect of $C$. longa on blood glucose level and anxiety-like behavior in normoglycemic Swiss albino mice. A total of 20 mice were divided into four groups of five ( $n=5$ per group). Group I (control) received distilled water $10 \mathrm{ml} / \mathrm{kg}$, groups II, III, and IV received C. longa at $5 \%$, $10 \%$, and $20 \%$, respectively, for 14 days. We found that $20 \%$ C. longa group showed a significant $(p<0.05)$ increase in fasting blood glucose level $(195.84 \pm 14.46 \mathrm{mg} / \mathrm{dl})$ after 14 days of administration compared with the control group $(134.60 \pm 4.52 \mathrm{mg} / \mathrm{dl})$. We also found that $20 \%$ C. longa increased the anxiety-like behavior in normoglycemic Swiss albino mice compared with the control group. However, there was no significant $(p>0.05)$ difference in both fasting blood glucose level and anxiety-like behavior between the mice treated with $5 \%$ and $10 \%$ C. longa and the control group. This study indicates that $C$. longa at high concentration is unsafe for consumption by normoglycemic Swiss albino mice.
\end{abstract}

Keywords: Curcuma longa; anxiety-like behavior; blood glucose; depression

C2021 by Garkuwa et al. for use and distribution in accord with the Creative Commons Attribution (CC BY-NC 4.0) license (https://creativecommons.org/licenses/by-nc/4.0/), which permits unrestricted non-commercial use, distribution, and reproduction in any medium, provided the original author and source are credited.

\subsection{INTRODUCTION}

Diabetes mellitus (DM) affected more than 415 million people in 2015, and this figure is projected to double by 2040 . A reported prevalence of $0.8 \%$ to $11 \%$ involving rural and urban dwellers, with about $2 \%$ reported in Zaria, a semi-urban community in Northern Nigeria (Dahiru et al., 2008). The management of diabetes places a great burden on both individuals and the government. In 2015, the total global expenditure on diabetes was estimated to be between USD673 billion to USD1,197 billion, and this value is projected to rise to about USD802 to USD1,452 billion (Federation., 2019). In Nigeria, about USD500 million to USD5 billion is spent annually on diabetes (Federation., 2019).

Anxiety is an unpleasant state of inner turmoil, which causes nervous behavior such as fear, apprehension, and worries. It can lead to feelings of dread over something unlikely to happen, such as a feeling of imminent death (Alzahrani et al., 2017). Moreover, anxiety disorder is an emotion that is characterized by 
feelings of worrying thoughts, tension, and physical changes such as increased blood pressure (Alzahrani et al., 2017). Since anxiety disorder is common among patients with diabetes, with approximately $40 \%$ of these patients exhibiting it symptoms and a reported prevalence of about $14 \%$ (Grigsby et al., 2002), a strong relationship between diabetes mellitus, major depression, and anxiety disorder was established (Deschênes et al., 2015). Furthermore, major depression and anxiety disorders among patients with diabetes have been associated with poor glycaemic control, greater disability, and poor clinical outcome (Deschênes et al., 2015; Whitworth et al., 2016).

There are several forms of anxiety, including generalized anxiety disorder (GAD), social anxiety disorder, panic disorder, and specific phobias (Dew et al., 2004). GAD is an extravagant tension and worries about daily calamities and problems on most days. This disorder can last for at least 24 weeks, and the patient experiences difficulty in performing day-to-day tasks (Kessler \& Wittchen, 2002). Additionally, some GAD symptoms include autonomic hyperactivity, increased motor tension, and increased vigilance and scanning with lacking panic attacks (Singewald et al., 2015).

Depression comes because of anxiety and affects approximately $21 \%$ of the world populace (Organization, 2017). Curcumin, a major constituent of Curcuma longa, demonstrated anti-inflammatory, anticancer, and anti-oxidant (Deogade \& Ghate, 2015), anti-hyperlipidemic (Pari \& Murugan, 2007), and antianxiety activities (Lee \& Lee, 2018) in both in vitro and in vivo experimental settings. Therefore, the need to search for safer and cost-effective management for these disorders cannot be overemphasized. However, there is a need to investigate its safety in normoglycemic mice. While many studies on the effect of $C$. longa (turmeric) on diabetic mice, there is a paucity of data on its effect on normoglycemic mice. Also, diabetes and anxiety-like behavior have been linked but poorly investigated. Hence, this study determined the effect $C$. longa on blood glucose level and anxiety-like behavior in normoglycemic Swiss albino mice.

\subsection{MATERIALS AND METHODS}

\subsection{Animals and supplementation of curcumin}

A total of twenty Swiss albino mice weighing 20-30 g were housed in plastic cages under standard laboratory conditions with free access to food and water for two weeks to acclimatize in the laboratory environment before starting the experiments. Ethical clearance was obtained from the Ahmadu Bello University Committee on Animal Use and Care (ABUCAUC/051) and in accordance with the ethical standards laid down in the 1964 Declaration of Helsinki. All drugs and reagents were obtained commercially and are of analytical grade. C. longa was obtained from the College of Agriculture, Bauchi State. Mr. Modibbo Sale of the Forestry Department identified the plant and gave it a voucher number of 1466. The rhizomes of the turmeric were first washed and sliced into pieces, and dried. The dried rhizomes were then ground to a fine powder. A digital glucometer (an Accu-Check Advantage, Roche Diagnostic, Germany) was used to determine the blood glucose level of the animals. The animals were divided into four groups of five mice each and fed with an appropriate combination of thoroughly mixed vital feed and C. longa for 14 days as described in Table 1.

Table 1: Composition of animal feed for each group

\begin{tabular}{ll}
\hline Groups & Treatments \\
\hline Group I & $\begin{array}{l}\text { Distilled water and 100\% vital feed (9.7\% moisture, } 2 \% \text { ash, } 9 \% \text { crude fiber, } 10 \% \text { fat, } 20 \% \text { crude protein and } \\
49.3 \% \text { carbohydrate), }\end{array}$ \\
\hline Group II & $\begin{array}{l}\text { C. longa } 5 \% \text { and } 95 \% \text { of vital feed (9.2\% moisture, } 1.9 \% \text { ash, } 8.6 \% \text { crude fiber, } 9.5 \% \text { fat, } 19 \% \text { crude protein } \\
\text { and } 46.8 \% \text { carbohydrate), }\end{array}$ \\
\hline Group III & $\begin{array}{l}\text { C. longa } 10 \% \text { and } 90 \% \text { of vital feed ( } 8.7 \% \text { moisture, } 1.8 \% \text { ash, } 8.1 \% \text { crude fiber, } 9 \% \text { fat, } 18 \% \text { crude protein and } \\
44.4 \% \text { carbohydrate) }\end{array}$ \\
\hline Group IV & $\begin{array}{l}\text { C. longa } 20 \% \text { and } 80 \% \text { of vital feed ( } 7.8 \% \text { moisture, 1.6\% ash, 7.2\% crude fiber, } 8 \% \text { fat, } 16 \% \text { crude protein and } \\
39.4 \% \text { carbohydrate) }\end{array}$ \\
\hline
\end{tabular}




\subsection{Estimation of blood glucose level}

We obtained the blood sample from sequential snipping off the tail in accordance with Fluttert et al. (2000). Animals fasted for approximately $12 \mathrm{~h}$ (overnight) before the determination of fasting blood glucose level (Sun et al., 2016). A digital glucometer was used to measure the blood glucose level (Beach \& Turner, 1958), and results were recorded in $\mathrm{mg} / \mathrm{dL}$.

\subsection{Elevated plus maze (EPM) for anxiety assessment}

An elevated plus-maze (EPM) test was conducted as previously described (Komada et al., 2008). The elevated plus-maze consists of two open arms $(28 \times 5$ $\mathrm{cm})$ and two closed arms $(30 \times 5 \mathrm{~cm})$ with a $15 \mathrm{~cm}$ high wall. The arms and central square were made of wooden plates elevated $51 \mathrm{~cm}$ above the floor. Notably, the arms of the same type are located opposite from each other. Each mouse was placed in the central square of the maze $(5 \times 5 \mathrm{~cm})$, facing one of the closed arms. Then, the behavior of the mouse, including the time spent in the open and closed arm, were recorded and analyzed during a 5 min test period. The mice were subjected to EPM test 3 times, and the average measurement was used.

\subsection{Statistical analysis}

Data obtained were expressed as mean \pm standard error of the mean (SEM). One-way analysis of variance (ANOVA) followed by Tukey's multiple comparison post hoc tests to compare the level of significance between control and experimental groups was used to analyze the data using SPSS software version 22. Statistical tests with $p<0.05$ were considered significant.

\subsection{RESULTS}

To determine whether $C$. longa supplementation affected fasting blood glucose level, we checked the blood glucose level weekly and observed a statistically significant means difference $[F(3)=5.284, p<0.001]$ (Table 2) in the fasting blood glucose level between controls and the treatment groups. Moreover, result from Tukey's multiple comparison post hoc tests showed a statistically significant increase $(p<0.05)$ in the fasting blood glucose level in the $20 \%$ C. longa supplemented group compared to the control, $5 \%$ and $10 \%$ supplemented groups, respectively (Table 2 ). Hence, C. longa at $5 \%$ and $10 \%$ did not affect fasting blood glucose level on Swiss albino mice $(p>0.05)$.

Table 2: Effect of $C$. longa Supplement on Fasting Blood Glucose Level of Normoglycemic Swiss albino mice

\begin{tabular}{lccc}
\hline Groups & Day 0 (mg/dl) & Day 7 (mg/dl) & Day 14 (mg/dl) \\
\hline Control & $87.64 \pm 5.70$ & $111.04 \pm 2.69$ & $114.60 \pm 4.52$ \\
\hline C. longa 5\% & $97.20 \pm 10.84$ & $126.00 \pm 8.50$ & $130.60 \pm 3.78$ \\
\hline C. longa 10\% & $97.80 \pm 15.76$ & $133.80 \pm 15.76$ & $115.08 \pm 9.57$ \\
\hline C. longa 20\% & $98.28 \pm 7.46$ & $130.68 \pm 9.48$ & $195.84 \pm 14.46^{*}$ \\
\hline
\end{tabular}

Note: Values with asterisks $\left({ }^{*}\right)$ superscript are statistically significant $\mathbf{F}(\mathbf{3})=\mathbf{5 . 2 8 4}(p<0.001)$

To determine whether $C$. longa supplementation affected anxiety-like behavior, we used the elevated plus maze test and recorded the time spent by each mouse exploring both open and closed arms. In the time spent in the open arm, no statistically significant $(p>0.05)$ difference between the mean of the control group $(223.40 \pm 6.38 \mathrm{~s})$ and the means of the treated groups $(220.20 \pm 16.17 \mathrm{~s}, 200.40 \pm 2.38 \mathrm{~s}, 200.00 \pm 4.09 \mathrm{~s}$ for Groups II, III and IV, respectively) (Figure 1). However, a statistically significant increase $[F(3)=8.381$, $p<0.001$ ] (Figure 2) in the time spent in closed arms between control and treatment groups. Moreover, the result from Tukey's multiple comparison post hoc analysis revealed a significant increase $(p<0.05)$ in the time spent in the closed arms in the $20 \% C$. longa supplemented group compared to the control, $5 \%$ and $10 \%$ supplemented groups, respectively (Figure 2).
Contrarily, C. longa at $5 \%$ and $10 \%$ have no effect on the time spent in the closed arm.

\subsection{DISCUSSION}

Diabetes and depression are highly prevalent conditions with a significant impact on health outcomes (Egede \& Ellis, 2010). Recent studies have suggested a strong relationship between diabetes and depression. While some of these studies suggested bidirectional relationship (Knol et al., 2006), this relationship needs to be backed with a research-based evidence aimed at understanding the mechanism of increased anxiety and depression resulting from diabetes and vice versa. From the findings of this study, it was observed that high concentration $C$. longa treated groups (Group IV; $195.84 \pm 14.46 \mathrm{mg} / \mathrm{dL}$ ) 


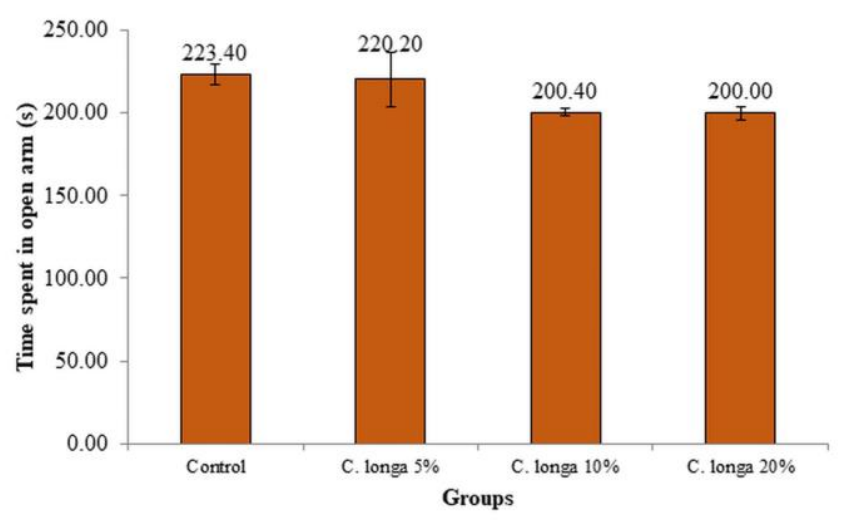

Figure 1. Effect of $C$. longa Supplement on Anxiety-like Behavior in Normoglycemic Swiss albino mice (Open Arm).

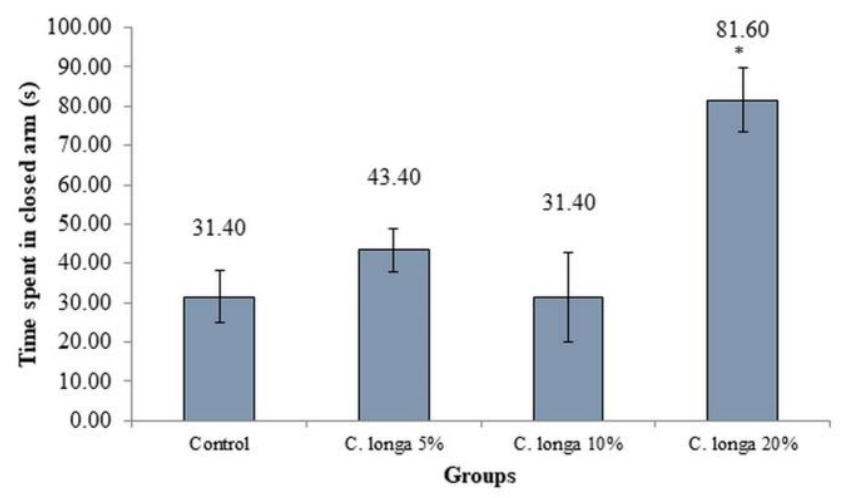

Figure 2. Effect of $C$. longa Supplement on Anxiety-like Behavior in Normoglycemic Swiss albino mice (Closed Arm). Values having asterisks $\left({ }^{*}\right)$ are statistically significant $(\mathrm{F}(3)=$ 8.381, $(p<0.001)$

showed a significant $(p<0.05)$ increase in fasting blood glucose levels after 14 days of administration compared with the control group (group I; $134.60 \pm 4.52$ $\mathrm{mg} / \mathrm{dL}$ ) (Table 1). The physiological bases for this increase remain unclear, as previous studies using $C$. longa on diabetic mice showed that $C$. longa is antihyperglycemic (Den Hartogh et al., 2020; Hodaei et al., 2019). The result of this study shows that $C$. longa at high concentration could be harmful to normal mice.

The elevated plus-maze test is an open field test that assesses anxiety-like behaviors in experimental animals (Lee \& Lee, 2018). We observed no difference in the time spent in the open arm (Figure 1). The increased proportion of the time spent in the open arm indicates a reduction or decrease in anxiety (Carobrez \& Bertoglio, 2005). However, in the time spent in the closed arm, there was a statistically significant difference in the group that received $C$. longa 20\% $(p<0.05)$ compared with the control and C. longa $5 \%$ and $10 \%$ groups (Figure 2). This result indicated that the $C$. longa at this percentage might not be healthy for the experimental animals.

An increase in the proportion of time spent in closed arms indicates an increase in anxiety (Carobrez \& Bertoglio, 2005). Therefore, our study further justifies this assertion, as shown in Table 2, where $C$. longa supplementation at $20 \%$ significantly $(p<0.05)$ increases the blood glucose level. Hence, the rise in the blood glucose level might have affected the experimental animals, which stimulate the amygdaloid nucleus in the limbic system or by direct stimulation of the fear center in the periventricular nucleus of the hypothalamus leading to appropriate autonomic response such as sweating, pupil dilatation and side seeking escape (Carobrez \& Bertoglio, 2005; Holt et al., 2014). Ultimately, a low dose of C. longa may be associated with improved anxiety and blood glucose levels (Comin et al., 2010).

The findings of this study might have been affected by the duration of the study, the doses used, or the paradigm used for assessing anxiety-like behavior. Previous studies showed that EPM is inconsistent in anxiety-like behavior assessment, hence raising issues concerning its validity (Carobrez \& Bertoglio, 2005). EPM had been reported to produce mixed results concerning agents such as valium (benzodiazepine) (Carobrez \& Bertoglio, 2005). Therefore, it is recommended that this same work using other models for the screening of anxiety-like behavior and depression should be employed to test further the effect of this substance on experimental animals. Passive avoidance tests and other parameters such as the number of arm entries need to be taken and analyzed. Also, the mechanism through which $C$. longa at $20 \%$ increased fasting blood glucose level is recommended for further investigation.

\subsection{CONCLUSIONS}

From the experimental observation, it has been shown that $C$. longa supplement at higher concentration is not suitable for normoglycemic Swiss albino mice with the report of an increase in anxiety-like behavior. It also suggested the need for further studies on the mechanism underlying the increased anxiety-like behavior in $C$. longa supplemented animals at high concentration.

Acknowledgments: Authors want to express their gratitude to the Ahmadu Bello University Committee on Animal Use and Care, and Head of the Department of Physiology, who 
permitted the study, laboratory staff, and students who helped in the handling and feeding of the animals.

Author Contributions: UAG conceptualized the design of the study. UAG, BI, AHG, and ABY supervised the study, prepared the first draft of the manuscript. ANB, SRM, and
MM helped in the data collection and analysis. All authors contributed and agreed to the final version of the manuscript.

Conflicts of Interest: The authors declare no conflict of interest.

\section{References}

Alzahrani, M., Alfahaid, F., Almansour, M., Alghamdi, T., Ansari, T., Sami, W., Otaibi, T. M. Al, Humayn, A. A. Al, \& Enezi, M. M. Al. (2017). Prevalence of generalized anxiety disorder and major depression in health-care givers of disabled patients in Majmaah and Shaqra cities, Kingdom of Saudi Arabia. International Journal of Health Sciences, 11(3), 9-13. http://www.ncbi.nlm.nih.gov/pubmed/28936144

Beach, E. F., \& Turner, J. J. (1958). An enzymatic method for glucose determination in body fluids - PubMed. Clinical Chemistry, 4(6), 462-475. https://pubmed.ncbi.nlm.nih.gov/13608908/

Carobrez, A. P., \& Bertoglio, L. J. (2005). Ethological and temporal analyses of anxiety-like behavior: The elevated plus-maze model 20 years on. Neuroscience and Biobehavioral Reviews, 29(8), 1193-1205. https://doi.org/10.1016/j.neubiorev.2005.04.017

Comin, D., Gazarini, L., Zanoni, J. N., Milani, H., \& de Oliveira, R. M. W. (2010). Vitamin E improves learning performance and changes the expression of nitric oxide-producing neurons in the brains of diabetic rats. Behavioural Brain Research, 210(1), 38-45. https://doi.org/10.1016/j.bbr.2010.02.001

Dahiru, T., Jibo, A., Hassan, A. A., \& Mande, A. T. (2008). Prevalence of diabetes in a semi-urban community in Northern Nigeria. Nigerian Journal of Medicine : Journal of the National Association of Resident Doctors of Nigeria, 17(4), 414-416. https://doi.org/10.4314/njm.v17i4.37423

Den Hartogh, D. J., Gabriel, A., \& Tsiani, E. (2020). Antidiabetic properties of curcumin ii: Evidence from in vivo studies. Nutrients, 12(1), 58. https://doi.org/10.3390/nu12010058

Deogade, S. C., \& Ghate, S. (2015). Curcumin: therapeutic applications in systemic and oral health. International Journal of Biological \& Pharmaceutical Research, 6(4), 281-290.

Deschênes, S. S., Burns, R. J., \& Schmitz, N. (2015). Associations between diabetes, major depressive disorder and generalized anxiety disorder comorbidity, and disability: Findings from the 2012 Canadian Community Health Survey - Mental Health (CCHS-MH). Journal of Psychosomatic Research, 78(2), 137-142. https://doi.org/10.1016/i.jpsychores.2014.11.023

Dew, M. A., Myaskovsky, L., Dimartini, A. F., Switzer, G. E., Schulberg, H. C., \& Kormos, R. L. (2004). Onset, timing and risk for depression and anxiety in family caregivers to heart transplant recipients. Psychological Medicine, 34(6), $1065-1082$. https://doi.org/10.1017/S0033291703001387

Egede, L. E., \& Ellis, C. (2010). Diabetes and depression: Global perspectives. Diabetes Research and Clinical Practice, 87(3), 302-312. https://doi.org/10.1016/j.diabres.2010.01.024

Federation, I. D. (2019). IDF Diabetes Atlas, 9th edn. https://www.diabetesatlas.org

Fluttert, M., Dalm, S., \& Oitzl, M. S. (2000). A refined method for sequential blood sampling by tail incision in rats. Laboratory Animals, 34(4), 372-378. https://doi.org/10.1258/002367700780387714

Grigsby, A. B., Anderson, R. J., Freedland, K. E., Clouse, R. E., \& Lustman, P. J. (2002). Prevalence of anxiety in adults with diabetes a systematic review. Journal of Psychosomatic Research, 53(6), 1053-1060. J Psychosom Res. https://doi.org/10.1016/S0022-3999(02)00417-8

Hodaei, H., Adibian, M., Nikpayam, O., Hedayati, M., \& Sohrab, G. (2019). The effect of curcumin supplementation on anthropometric indices, insulin resistance and oxidative stress in patients with type 2 diabetes: A randomized, doubleblind clinical trial. Diabetology and Metabolic Syndrome, 11(1), 14. https://doi.org/10.1186/s13098-019-0437-7

Holt, R. I. G., De Groot, M., \& Golden, S. H. (2014). Diabetes and depression. Current Diabetes Reports, 14(6), 491. https://doi.org/10.1007/s11892-014-0491-3

Kessler, R. C., \& Wittchen, H. U. (2002). Patterns and correlates of generalized anxiety disorder in community samples. Journal of Clinical Psychiatry, 63(SUPPL. 8), 4-10. https://pubmed.ncbi.nlm.nih.gov/12044107/

Knol, M. J., Twisk, J. W. R., Beekman, A. T. F., Heine, R. J., Snoek, F. J., \& Pouwer, F. (2006). Depression as a risk factor for the onset of type 2 diabetes mellitus. A meta-analysis. Diabetologia, 49(5), 837-845. https://doi.org/10.1007/s00125-006$\underline{0159-x}$

Komada, M., Takao, K., \& Miyakawa, T. (2008). Elevated plus maze for mice. Journal of Visualized Experiments, $22(22), 1088$. https://doi.org/10.3791/1088

Lee, B., \& Lee, H. (2018). Systemic Administration of Curcumin Affect Anxiety-Related Behaviors in a Rat Model of Posttraumatic Stress Disorder via Activation of Serotonergic Systems. Evidence-Based Complementary and Alternative Medicine, 2018, 9041309. https://doi.org/10.1155/2018/9041309

Organization, W. H. (2017). Depression and Other Common Mental Disorders: Global Health Estimates. https://www.who.int/mental health/management/depression/prevalence global health estimates/en/ 
Pari, L., \& Murugan, P. (2007). Anti-hyperlipidemic effect of curcumin and tetrahydrocurcumin in experimental type 2 diabetic rats. Renal Failure, 29(7), 881-889. https://doi.org/10.1080/08860220701540326

Singewald, N., Schmuckermair, C., Whittle, N., Holmes, A., \& Ressler, K. J. (2015). Pharmacology of cognitive enhancers for exposure-based therapy of fear, anxiety and trauma-related disorders. Pharmacology and Therapeutics, 149, 150-190. https://doi.org/10.1016/j.pharmthera.2014.12.004

Sun, C., Li, X., Liu, L., Canet, M. J., Guan, Y., Fan, Y., \& Zhou, Y. (2016). Effect of fasting time on measuring mouse blood glucose level. International Journal of Clinical and Experimental Medicine, 9(2), 4186-4189.

Whitworth, S. R., Bruce, D. G., Starkstein, S. E., Davis, W. A., Davis, T. M. E., \& Bucks, R. S. (2016). Lifetime depression and anxiety increase prevalent psychological symptoms and worsen glycemic control in type 2 diabetes: The Fremantle Diabetes Study Phase II. Diabetes Research and Clinical Practice, 122, 190-197.

https://doi.org/10.1016/i.diabres.2016.10.023 